\title{
Diálogo entre o agnosticismo e o universo das religiões: o caso da empatia
}

Fermin Roland Schramm

\section{Resumo}

O artigo problematiza a possibilidade de diálogo entre duas cosmovisões consideradas antitéticas e excludentes, mas que podem ser vistas como separadas e complementares: o agnosticismo e a religião. Para tanto, introduz o conceito de empatia, condição considerada necessária para o diálogo entre subjetividades que queiram se relacionar e que é entendida como competência intelectual e emocional para compreender outrem e sua vivência, independentemente do fato do eu não poder reviver realmente a experiência vivenciada pelo outro. O diálogo empático, cujo sentido e história tentamos delinear a partir da análise conceitual e de sua contextualização no âmbito das ciências humanas, parece ser também a condição de possibilidade para a construção de um meta-ponto de vista complexo, capaz de ultrapassar, de modo argumentativo, uma suposta antítese entre agnosticismo e religião, em prol da própria sobrevivência dos atores do diálogo.

Palavras-chave: Secularismo. Empatia. Religião.

\section{Resumen}

\section{El diálogo entre el agnosticismo y el universo de las religiones: el caso de la empatía}

El artículo discute la posibilidad de diálogo entre dos visiones del mundo que se consideran antitéticas y excluyentes, pero que pueden ser vistas como independientes y complementarias: el agnosticismo y la religión. Para tanto introduce el concepto de empatía, que se considera condición necesaria para el diálogo entre las subjetividades que quieren relacionarse y entendida como capacidad intelectual y emocional para comprender a los otros y su experiencia, sin importar el hecho de que el Yo no puede vivir realmente la experiencia que pasado el otro. El diálogo empático, cuyo sentido y la historia se intenta dibujar a partir del análisis conceptual y su contextualización en el ámbito de las Humanidades, también parece ser la condición de posibilidad para la construcción de una meta-perspectiva compleja, capaz de superar argumentativamente un supuesto antítesis entre la religión y el agnosticismo, que debe ser superada dialécticamente por el bien de la supervivencia de los actores del diálogo.

Palabras-clave: Secularismo. Empatía. Religión.

\section{Abstract}

\section{Dialogue between agnosticism and the universe of faiths: the case of empathy}

The article discusses the possibility of dialogue between two worldviews considered as antithetical and mutually exclusive, but that can be seen as separate and complementary: Agnosticism and religion. Therefore, it introduces the concept of empathy, a condition considered necessary for dialogue between subjectivities that want to relate and understood as intellectual and emotional competence to understand others and their experience, regardless the fact that I really cannot relive an experience experienced by another person. The empathic dialogue, whose meaning and history we try to draw from the conceptual analysis and its contextualization within the Humanities, also seems to be the condition of possibility for the construction of a complex meta-perspective, able to overcome arguably an alleged antithesis between religion and agnosticism, which must be dialectically overcome for the sake of survival of the actors dialogue.

Keyword: Secularism. Empathy. Religion.

Doutor roland@ensp.fiocruz.br - Escola Nacional de Saúde Pública (Ensp/Fiocruz), Rio de Janeiro/RJ, Brasil.

\section{Correspondência}

Rua Augusto Severo 132, apto. 1.201, Glória CEP 20021-040. Rio de Janeiro/RJ, Brasil. 
Por mais egoísta que se suponha o homem, evidentemente há alguns princípios em sua natureza que o fazem interessar-se pela sorte dos outros. [O] mais empedernido infrator das leis da sociedade [não] é totalmente desprovido desse sentimento. Adam Smith ${ }^{1}$

O fenômeno discursivo, designado pelo termo "diálogo", pode ser visto como possuindo, pelo menos, dois aspectos: um teórico e outro prático, que devem ser considerados como distintos e interligados, ou, como diríamos hoje, como constituintes de uma relação complexa. De acordo com a filologia,

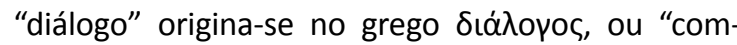
partilhar o logos", e está aqui referido a uma possível relação empática entre "agnosticismo" (do grego $\alpha$-prefixo privativo + $\psi v \tilde{\omega} \sigma \iota \varsigma$, , "conhecimento", com os sentidos de "desconhecido" ou "não cognoscível") e "religião" (do latim religio, de [a] religare, que possui os sentidos de "laço" e "obrigação" para com determinadas práticas ou entre humanos e entre estes e os deuses, e [b] relegere, com os sentidos de "reler" e "rever com cuidado" ou "recolher" e "reunir") 2 .

Historicamente, costuma-se distinguir, a partir da "Metafísica" de Aristóteles, o saber teórico, referido às coisas consideradas necessárias, e o saber prático, referente às contingências, sendo que, juntos, os dois tipos de saber orientariam a ação política e ética; ou seja, trata-se de dois tipos de saberes distintos, que podem ser vistos como opostos, mas não como separados, por referirem-se a um tipo de razão que exclui tal separação, chamada razão prática.

A distinção entre teoria e prática (ou entre razão teórica e razão prática) será retomada e reformulada por Kant, que distinguia a racionalidade teórica (que responderia à pergunta Que posso saber?) e a racionalidade prática, (referida a Que devo fazer?), sendo, portanto, ambos os aspectos relacionados ao denominador comum "razão" (logos, ratio). E devendo-se considerar que (a) o uso teórico da razão [ocupa-se] com objetos da simples faculdade de conhecer, mas que facilmente se perde, acima de seus limites, entre objetos inalcançáveis ou entre conceitos reciprocamente discordantes, e que, no caso de seu "uso prático", (b) a razão ocupa-se com fundamentos determinantes da vontade [e,] na medida em que se trata somente do querer, possui sempre realidade objetiva ${ }^{3}$. Na sua terceira crítica crítica do juízo - Kant reitera a distinção entre essas duas faces da razão, mas afirma que haveria uma passagem entre elas, representada pela faculdade do juízo, que na ordem das nossas faculdades de conhecimento constitui um termo médio ou um elo intermediário entre o entendimento e a razão, ou seja, a faculdade do juízo seria a capacidade de ajustar a faculdade da imaginação ao entendimento ${ }^{4}$.

Abordaremos aqui esta relação complexa entre teoria e prática, mas tão somente a partir do aspecto teórico da questão de um possível diálogo entre agnosticismo e religião, deixando o aspecto prático para ulteriores reflexões e concentrando-nos, prioritariamente, na abordagem conhecida como "análise conceitual", entendida como processo [de] explicar um conceito, uma crença, uma teoria [...], chamando a atenção para seus constituintes, seus pressupostos, suas implicações [e que] pode servir como base para uma avaliação crítica ${ }^{5}$. Neste sentido, embora seja o foco, o aspecto teórico, ao ser contextualizado, encontra a razão prática, quando esta se ocupa do fato, amplamente constatável no campo da ética prática, das dificuldades de comunicação nos casos de conflitos concretos entre agentes sociais, que são devidas, por sua vez, ao diferente uso dos conceitos na argumentação que visa justificar as práticas de um agente moral quando confrontado com um conflito de valores e de interesses subjacente a uma controvérsia determinada a ser resolvida.

No caso específico aqui em exame, a face teórica da pergunta sobre o "diálogo" diz respeito às condições de possibilidade de sua existência entre dois tipos de crença prima facie excludentes: (a) aquela que consiste em acreditar que a razão deve "suspender seu juízo" ou "pôr entre parênteses" os problemas metafísicos e religiosos - indicada pelo termo agnosticismo; e (b) aquela que se ocupa da relação que o humano estabelece com o sagrado e a(s) divindade(s) - indicada pelo termo religião. Em resumo, a pergunta é se é possível diálogo entre posições em princípio logicamente antagônicas, representadas pelo(s) agnosticismo(s) e a(s) religião(ões).

Aparentemente, a resposta a tal pergunta só pode ser negativa, pois o diálogo entre um agnóstico e um religioso parece ser impossível, devido à falta de um denominador comum "compartilhável" entre suas "visões de mundo" antagônicas. A inexistência de intersecção clara entre o agnóstico (para quem é impossível saber se Deus existe e pode ser representado na afirmação não podemos sequer saber que perguntas fazer no que se refere a certos assuntos ${ }^{6}$ ) e o religioso, cuja atenção escrupulosa prestada a signos [...], manifestações externas ao indivíduo ou, ao contrário, modificações no plano psicológico [e que] não se aplica exclusivamente à esfera dos deuses $^{7}$, remete à mesma relação que, a fortiori, se estabelece entre $o$ ateu (que simplesmente nega a existência de qualquer ser divino, considerando-a portanto uma questão não pertinente) e o religioso 
fundamentalista (que nega qualquer crença diferente da sua e recusa qualquer versão de um mundo e uma sociedade secularizados).

A justificativa muitas vezes utilizada para tentar sustentar com fatos reais tal resposta negativa é que bastaria olharmos para os conflitos, tanto do passado como atuais, entre fundamentalismo religioso e democracia laica para nos darmos conta de que estamos longe de uma situação em que podemos dizer, com propriedade, que a humanidade esteja efetivamente "compartilhando o logos" para que "crentes" e "não crentes" se compreendam e convivam sem se machucar e eliminar, aceitando e compartilhando suas diferenças recíprocas para "compensar" a incompletude existencial e experiencial que nos caracteriza como seres finitos (e mortais). A tese defendida é, portanto, que o diálogo não existiria se considerarmos os atuais conflitos e características, como acontece com o fundamentalismo, que confunde explicitamente política e religião e, propositadamente, Estado e Igreja, o que torna a relação dialógica impossível, já que não existe um denominador comum entre as partes em conflito, nem estas manifestam intenção de sair dele.

Entretanto, esta aparente impossibilidade prática pode ser contornada adotando, por exemplo - de acordo com a proposta da hospitalidade incondicional e de perdão de Derrida -, uma lógica da ética hiperbólica, que implicaria outorgar o perdão lá onde este não é nem pedido nem merecido, $e$ mesmo para o pior do mal radical, pois o perdão só adquire seu sentido [e] só encontra a sua possibilidade de perdão onde é chamado a fazer o impossível e a perdoar o imperdoável ${ }^{8}$.

Esta solução prática "incondicional" proposta por Derrida será, no entanto, abordada aqui só indiretamente, pois não entraremos nos meandros das possibilidades/impossibilidades de se pensar a questão metafísica da relação com o outro em geral, "relação" entendida como este "Iaço" fiduciário [que] precederia toda comunidade determinada, toda religião positiva, todo horizonte onto-antropoteológico e que religaria puras singularidades antes de qualquer determinação social ou política, antes toda intersubjetividade, e mesmo antes a oposição entre o sagrado (e o santo) e o profano, o que pode ser interpretado como uma desertificação que torna possivel, abre, escava ou infinitiza o outro, inclusive no sentido de tornar possível aquilo mesmo que ela parece ameaçar ${ }^{9}$. Em outros termos, aqui tentaremos percorrer outro caminho, mais modesto: procurando o que poderia, pelo menos conceitualmente, relacionar os dois campos aparentemente antitéticos, reformulando a pergunta e tentando ver se existem características do diálogo que permitam pôr em contato sistemas e visões de mundo em princípio logicamente opostos.

Aqui partiremos da hipótese de que uma das condições de possibilidade é que o diálogo entre tais Weltanschauungen seja visto como relação entre diferenças, ou seja, como diálogo empático, en-

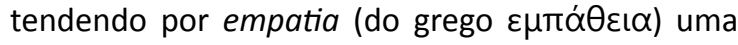
forma discursiva aberta ou de compartilhamento do logos com outrem; como uma atitude não diretiva de compreensão do outro capaz de compreender a vivência de outra pessoa sem, no entanto, poder concretamente experimentá-la realmente ${ }^{10}$.

Defenderemos, em particular, a ideia de que a relação intersubjetiva dita "empática" seja considerada condição necessária (embora talvez não a única) para poder falar, com propriedade, em diálogo, pois as palavras (e os conceitos) "diálogo" e "empatia" se implicam reciprocamente, visto que a empatia consiste em tentar se colocar no lugar do outro, mas sabendo que tal projeto demanda aceitar, em última instância, a absoluta transcendência do outro, o que tornaria a relação eu-outro não de identidade, mas de diferenças (representadas aqui pelos casos do agnosticismo e da religião).

A seguir, tentaremos mostrar tal ideia a partir da análise conceitual dos termos "diálogo", "empatia", "agnosticismo" e "religião", envolvidos na questão do diálogo entre partes.

\section{Análise conceitual}

\section{Diálogo}

De acordo com as ciências da linguagem, diálogo pode ser conceituado como a forma discursiva (chamada também de interlocução) que (a) põe o acento sobre o alocutário, isto é, foca o destinatário de um ato linguístico; que (b) se refere abundantemente à situação alocutiva; e (c) que atua em vários quadros de referência simultaneamente ${ }^{11}$. Neste sentido, quando relativo a vários quadros de referência, um diálogo só aconteceria na presença de uma "diferença" entre atores envolvidos, seus argumentos e suas referências. Tal diferença é o que impede que o diálogo se confunda com monólogo, isto é, fala sem interlocução propriamente dita, que exclui a diferença.

Em outros termos, uma condição de possibilidade para a existência da forma discursiva chamada diálogo é que sejam respeitadas determinadas premissas, a começar, por exemplo, pela tolerância, en- 
tendida como a atitude de se abster de agir contra o que reprovamos, contra o que nos é politicamente contrário ou contra o que é diferente de nós, sendo considerada em matéria religiosa um dos bastiões do Estado democrático moderno, embora continue sendo um conceito problemático, pois implica sabermos compreender como um princípio de tolerância pode coexistir com a conviç̧ão moral e religiosa genuína ${ }^{12}$.

Ademais, tolerância é uma condição que podemos chamar de mínima para que exista diálogo, sendo sua condição máxima - que podemos chamar também de plena - a aceitação incondicional do absolutamente outro, a qual constitui, em nosso entender, a característica específica do tipo de diálogo entre diferenças, que chamamos de empático.

Partindo do pressuposto da necessidade incondicional da existência do outro para que o eu exista na estrutura constituída pelo compartilhamento do logos, representado pelo diálogo, poderíamos entender por diálogo empático um discurso baseado na racionalidade comunicativa, considerada como sendo ao mesmo tempo analítica, crítica e normativa, de acordo com a proposta do agir comunicativo de Habermas ${ }^{13}$, que implica uma ética discursiva fundada no necessário reconhecimento do outro, sem o qual não haveria propriamente diálogo.

Entretanto, este reconhecimento pode ser pensado de duas formas diferentes: (a) como reconhecimento recíproco entre eu e outro, que permita que as pessoas sejam agentes comunicativos e solidários de uma sociedade ${ }^{14} \mathrm{em}$ que as pessoas, adotando o princípio ético fundamental do diálogo, tornem-se agentes moralmente competentes, capazes de expressar a vontade moral de compreender os outros e de se tornar compreensiveis para os outros, mas tendo em conta que não há nenhuma regra para pensar, mas tão somente regras para outros aspectos de nosso comportamento ${ }^{15}$ ou; (b) como reconhecimento radical do outro, que, de acordo com Levinas, implica aceitar que o espaço intersubjetivo não é simétrico, pois o outro não é, de nenhuma maneira, outro mim-mesmo, embora participe de uma existência comum. Por isso, a relação com outrem não deveria ser vista como uma idílica e harmoniosa relação de comunhão, nem como uma simpatia por meio da qual, nos colocando em seu lugar, o reconhecemos parecido com nós, podendo-se até dizer que a relação com o outro é a relação com um Mistério ${ }^{16}$ e que a relação intersubjetiva só se daria como relação de um a outro e na transcendência do 'para-o-outro' que instauram o 'sujeito ético', que instauram o entre-nós ${ }^{17}$.
Das duas propostas, a mais exigente é, evidentemente, aquela de Levinas, a qual parece requerer o conceito de empatia aqui proposto, ao passo que a proposta de Habermas parece basear-se no conceito tradicional de simpatia, que implica alguma forma de reciprocidade prévia entre eu e outro para que haja de fato diálogo, além, portanto, da atitude de mera tolerância frente a alteridade. Seguiremos então a proposição de Levinas, que nos parece mais pertinente para abordar a questão da empatia e do tipo de diálogo exigente que ela pressupõe.

Neste sentido, as "condições de possibilidade" para a existência do diálogo podem partir das observações de Levinas sobre "alteridade" e transcendência do outro, e tendo em conta que:

a) o outro é ente e conta como tal, isto é, o outro é fundamentalmente inassimilável ao eu;

b) a compreensão que posso ter do outro como possível ameaça pode implicar uma negação parcial, que é violência, [pois] nega a independência do ente [e o fato de que] ele depende de mim;

c) apesar [de] minha dominação sobre ele [...] não o possuo;

d) ele não entra inteiramente [no] campo de minha liberdade, devendo-se compreendê-lo a partir de sua história, do seu meio, de seus hábitos;

e) e isso pode implicar também que outrem é o único ente cuja negação não pode anunciar-se senão como tal, [pois] outrem é o único ser que posso [inclusive] querer matar ${ }^{18}$.

Em suma, de acordo com Levinas, a não aceitação da alteridade de outrem pode demandar, em última instância, sua eliminação, o que é justamente o contrário do resultado esperado do diálogo; isto é, pode implicar a supressão de qualquer condição de possibilidade de diálogo empático entre eu e outro.

\section{A relação entre diálogo e dialética}

A palavra "diálogo" possui de fato proximidade

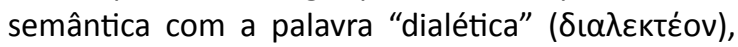
ou arte do diálogo), a qual pode ser explicada por diversas linhas interpretativas que não são isoladas entre si e entre as quais se estabelecem trocas, entrelaçamentos, contaminações, que tornam o quadro geral bastante movido e variegado ${ }^{19}$.

Em suma, a dialética foi entendida historicamente das seguintes maneiras: como método para refutar opiniões (Zenão de Eleia); como modelo dialógico em que se discutem questões e respostas (Sócrates); como método para obter o conhecimento racional (Platão); como uma forma de argumenta- 
ção para abordar opiniões (Aristóteles); como discussão crítica de posições antinômicas (Kant); como síntese dos opostos, na qual a dialética incorpora em sua lógica a contradição (Hegel); como método para compreender a realidade existente e para criticá-la e negá-la (Marx); como expressão da experiência das inter-relações entre sujeitos no campo comum da vida e aberto aos relacionamentos e contrastes das liberdades na história (Merleau-Ponty); como lógica vivente da ação em processo (Sartre); como forma chamada de dialética negativa, em que a categoria de totalidade deveria ser substituída por aquela de contradição (Adorno); ou como teologia dialética em que Deus é considerado como o totalmente outro frente ao qual o homem deveria considerar-se um nada (Barth) etc. ${ }^{19}$

Assim como "logos", o conceito de dialética possui um campo semântico denso e complexo, em que os sentidos concorrentes passam do grego às diferentes línguas europeias, adquirindo sua identidade contraditória e uma complexidade de uso ${ }^{20}$, sendo que esta caracterização diz respeito também ao diálogo. Em suma, diálogo pode ser visto como o modo mais originário do acontecer da linguagem, como uma relação que se dá entre pelo menos dois seres humanos que são outros, em sentido rigoroso, um para o outro e que possui um futuro totalmente aberto, em que, através do originário realizar-se do homem em seu ser-no-mundo, pode tornar-se real algo novo, impossível de prever ${ }^{21}$.

Neste contexto, pode-se dizer que as condições de possibilidade para a existência de diálogo entre agnosticismo e religiões podem ser dadas adotando-se a postura agnóstica aberta ao outro, representado pelos religiosos, e sem necessariamente exigir, em troca, o mesmo tipo de atitude da parte do outro, por ele ser considerado - de acordo com as sugestões de Levinas - objeto de minha responsabilidade absoluta, a qual remete para a categoria de empatia, adotada aqui justamente para indicar a possibilidade de diálogo entre agnósticos e religiosos.

\section{Empatia}

De acordo com sua etimologia, o termo empa-

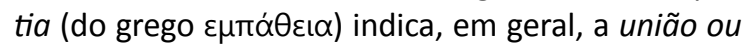
fusão emocional com outros seres ou objetos (considerados animados) ${ }^{22}$ ou, mais especificamente, a capacidade de compreender os sentimentos do outro, independentemente de compartilhar sua vivência e suas crenças. $O$ termo deve, portanto, ser distinto do

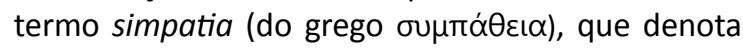
a capacidade de (supostamente) experimentar as mesmas emoções do outro, possibilidade excluída pelo termo "empatia".

De fato, só podemos experimentar empatia com alguém diferente de nós, não assimilável a nós; com alguém que é transcendente a nós, mas com quem queremos estabelecer alguma forma de diálogo, algo aparentemente impossível fora de uma lógica dialética capaz de integrar a contradição para tentar superá-la. A empatia estaria, portanto, baseada na impossibilidade de ocupar o lugar do outro e decorreria da capacidade de tão somente podermos experimentar nossa própria experiência com outras subjetividades, com outras comunidades e com a sociedade como um todo.

De acordo com a história das ideias, o termo aparece especificamente na cultura alemã, em particular no campo da estética, no qual surge, no final do século XVIII, o termo "Einfühlung", referido ao conhecimento de outras mentes. Será traduzido para o inglês, já no século XX, por "empathy", que se torna comum, sobretudo em psicologia, para designar comportamentos altruísticos e, no campo emergente das neurociências, um novo paradigma para designar uma correlação neuronal que seria a base biológica da socialidade, sendo, por isso, um termo bastante discutido devido à acusação de reducionismo positivista, feita especialmente por filósofos e cientistas sociais ${ }^{23}$.

Em particular, "Einfühlung" foi adotado pelo fenomenólogo Husserl que, preocupado com a constituição do conhecimento objetivo e as configurações da vida prática, utilizou-o para indicar o fato de que não podemos conhecer os pensamentos e os sentimentos do outro, que permanecem opacos, pois tenho em mim [...] a experiência do 'mundo' $e$ dos 'outros' [...] não como de uma obra de minha atividade sintética de alguma forma privada, mas como de um mundo estranho a mim ${ }^{24}$. Husserl - que será retomado por Levinas - mantém firme a distinção entre o sujeito empatizante e seu referimento intencional, ou seja, a vivência psíquica de outrem ${ }^{25}$.

Atualmente, podemos dizer que o termo refere-se a uma constelação de experiências, muitas vezes bastante diferentes entre si e que dificilmente podem ser todas reconduzidas a um denominador comum ${ }^{26}$, embora seja possível dizer - de acordo com as preocupações da razão prática (e, portanto, da ética e da política) - que a empatia pressupõe a vulnerabilidade humana, que implica o reconhecimento da fragilidade da existência humana e o apelo à consequente responsabilidade para com o outro. Ou seja, entende-se a característica humana universal da vulnerabilidade como a ponte que liga 
aqueles que $\mathrm{H}$. Tristram Engelhardt Jr. chamou de os estrangeiros no plano da moral numa sociedade pluralista ${ }^{27}$.

Em suma, empatia parece ser uma palavra guarda-chuva, pois remete a um conceito dúctil, situado numa constelação proteiforme e numa rede de parentescos categoriais que envolvem termos só parcialmente sobreponiveis, tais como projeção, transferência, associação, expressão, animação [e] fusão, o que implica atitudes distintas como ensimesmar, reviver, compadecer, consentir, imitar interiormente, simpatizar, sendo que isso mostraria, por um lado, a grande ductilidade dessa noção, mas também, por outro, os riscos de incompreensão demandados pela indistinção de seus contornos ${ }^{28}$. Por isso, o termo foi objeto de severas críticas, contestando sua pertinência e utilidade para a compreensão de nossa experiência do outro e das coisas, e até negando que à palavra corresponda, em última análise, algo comprovável e circunscritivel ${ }^{28}$.

Entretanto, nas últimas décadas, o uso do termo voltou, com força, nas expressões "civilização empática", "empatia global" e "Homo empathicus" (em substituição ao hobbesiano "homo homini lupus"), que, de acordo com o economista e ambientalista Jeremy Rifkin, visariam uma nova interpretação da história da civilização, a partir de uma nova visão radical da natureza humana, baseada numa evolução empática da raça humana, que pode decidir nosso destino enquanto espécie ${ }^{29}$.

Também para o primatólogo Frans de Waal, a empatia pertenceria à própria história evolutiva humana, sendo que, atualmente, está na moda [e] é o grande tema da nossa época, tratando-se de característica comportamental compartilhada com outros primatas e outros mamíferos, os quais possuiriam - de acordo com estudos de antropólogos, psicólogos, biólogos e neurocientistas - uma convergência emocional e que mostrariam que somos altamente cooperativos e sensíveis à injustiça. Nossa espécie tem um lado social e um lado egoísta, e nossos corpos e nossas mentes são feitos para a vida social, e nós nos tornamos desesperadamente deprimidos em sua ausência ${ }^{30}$.

Contra aqueles que contestam a pertinência e a legitimidade do uso do termo, o autor contra-argumenta que: quem quiser usar as atrocidades da guerra como argumento contra a empatia humana precisa pensar duas vezes, pois a guerra e o sentimento de empatia não se excluem mutuamente, $e$ é preciso considerar as dificuldades que a maioria dos homens sente de puxar o gatilho. Para reforçar, termina com uma pergunta: Por que essa dificulda- de [de "puxar o gatilho"] existiria se não fosse pela empatia dos seres humanos com os seus semelhantes? ${ }^{31}$. De fato, para o autor, a empatia promove a ligação entre os indivíduos e fornece a cada um deles uma 'participação' no bem-estar dos outros, encurtando a distância entre os benefícios diretos [e] os benefícios coletivos ${ }^{32}$, pois o sentimento de que não podemos ser indiferentes ao outro se quisermos construir uma comunidade que mereça esse nome é a outra força que sustenta as nossas interações ${ }^{33}$.

Em outros termos, a empatia seria uma forma de contágio emocional, e o vínculo é um elemento essencial para a nossa espécie, visto que não sentimos nada do que acontece fora de nós, mas, ao nos fundirmos inconscientemente com o outro, as experiências dele repercutem em nosso interior ${ }^{34}$.

Em suma, existiria uma constelação multiforme de fenômenos empáticos, a qual nos levaria a tentar re-escutar algum eco do antigo termo grego $\varepsilon \mu \pi \alpha \dot{\theta} \theta \varepsilon \alpha$, que estava a significar uma afecção do corpo, da carne ${ }^{35}$.

Feitas essas considerações conceituais sobre diálogo e empatia, podemos nos aproximar mais diretamente da questão do tipo de diálogo entre agnosticismo e religião também a partir da análise conceitual dos dois termos, que serão abordados juntos, ou seja, fazendo-os dialogar empaticamente entre si.

\section{Agnosticismo e religião}

O termo "agnosticismo" refere-se essencialmente à questão do não saber, isto é, à ignorância e, pelo menos desde Sócrates, ao ser consciente disso e que admite não saber. "Religião" pode designar tanto as práticas cultuais quanto as crenças que as legitimam, pelo menos desde o surgimento do cristianismo, cuja contribuição original consiste em [ter dado] um conteúdo doutrinal ao termo ${ }^{36}$.

Do ponto de vista doutrinal, o agnosticismo pode ser visto como a ideia de que a existência de Deus é impossível de ser conhecida e comprovada; diferentemente do ateísmo, que defende a ideia da não existência de Deus, ideia que também não pode ser demonstrada, provada ou refutada empiricamente para um agnóstico. Assim, o diálogo entre agnosticismo e religião só parece possível como polêmica sobre a atribuição de significados diferentes às palavras, pois:

- O agnosticismo pode ser visto como a corrente de pensamento (ou crença) que sustenta que 
aquilo que não pode ser verificado cientificamente é incognoscível, implicando, portanto, a suspensão (غ́похท́) do juízo frente a problemas religiosos, isto é, a crença que afirma a incapacidade do pensamento humano de ir "além" do âmbito da realidade constituída pelos fenômenos e de resolver os problemas metafísicos e religiosos;

- O universo das religiões ocupa-se justamente daquilo que o agnosticismo considera como objeto da suspensão do juízo, pelo menos se entendermos religião como dispositivo que pressupõe uma relação de dependência do homem [de] um ou mais seres superiores, dos quais o homem sabe depender e a quem presta determinado culto, ou seja, se a entendermos como um fenômeno que implica dois elementos: um objetivo, isto é, o complexo de relações entre a divindade e o homem, e outro subjetivo, que é a consciência da dependência e da consequente disposição no homem de devolver à divindade o culto que lhe pertence ${ }^{37}$.

Historicamente, o termo agnosticismo tem origem recente: o zoólogo inglês Thomas Henry Huxley (1825-1895) introduziu o termo inglês adjetivado "agnostic" em 1869 para indicar a atitude de quem considera "sem solução" os problemas metafísicos e religiosos porque ultrapassariam o mundo fenomênico e, portanto, não poderiam ser objetos de conhecimento válido, o qual só poderia ser obtido por meio do método científico. Nesse sentido, para Huxley o agnosticismo não seria uma crença, mas um método racional rigoroso, consistente na aplicação do princípio de não pretender que conclusões sejam certas sem serem demonstradas ou demonstráveis ${ }^{38}$.

Em seguida, o termo aparece em vários sistemas filosóficos, a começar pelo positivismo, sendo uma das condições de possibilidade de sua utilização no pensamento de Kant, para quem o entendimento humano (e seu produto representado pelo conhecimento e a teoria) é feito de representações, e não de intuições: o conhecimento de Deus é mera intuição, produto da vontade, e não um conhecimento teórico ou uma teoria de entes suprassensíveis, pois não somos absolutamente capazes de fundar um conhecimento especulativo, mas apenas de limitar seu uso à prática da lei moral. Ou seja, se abstraímos de todo o antropomorfismo nela [palavra agnosticismo], somente nos resta a simples palavra, sem poder vincular a ela o mínimo conceito pelo qual fosse permitido esperar uma ampliação do conhecimento teórico; em suma, o conceito de Deus não pertence nem à física nem à metafísica, mas à moral, pois mesmo pela metafísica e através de infe- rências seguras é impossivel chegar, do conhecimento deste mundo, ao conceito de Deus e à prova de sua existência ${ }^{39}$.

\section{Considerações finais}

De acordo com o embate entre agnósticos e religiosos, que acabamos de delinear, o diálogo parece ser da ordem do impossível. Entretanto, nossa tarefa foi indagar as condições de possibilidade para a existência, pelo menos na teoria, desse diálogo, o que tentamos mostrar introduzindo a categoria de empatia, motivada pela vontade de comunicar e de se relacionar com outrem, em particular com sua alteridade inassimilável ao eu.

Mas, como visto, a própria palavra "diálogo" possui proximidade semântica (um "ar de família", como dizia Wittgenstein ${ }^{40}$ ), com a palavra "dialética", a qual, por sua vez, possui diversas linhas interpretativas que não ficam isoladas entre si, e entre as quais se estabelecem trocas, entrelaçamentos, contaminações, que tornam o quadro geral bastante movido e variegado ${ }^{19}$. Não se pode esquecer que, desde Hegel, a lógica dialética inclui a contradição, o conflito.

Nesta abordagem do diálogo empático foi destacada a posição ética de Levinas, que opõe uma concepção ética ego-centrada (que ele recusa) e uma concepção altero-centrada (que aceita), baseada na transcendência irredutivel do Outro, devido a sua incognoscibilidade. Essa concepção implica, por um lado, uma responsabilidade incondicional do Eu com relação ao Outro e, por outro, a solução transcendente [que] consiste em implantar o Outro, antes de qualquer prática que seja, como um referente da subjetividade e com relação à qual o ator da prática deverá se definir e se situar, perspectiva na qual, afinal, são as iniciativas do Outro que modificam o horizonte das possibilidades [do Eu], e que, por exemplo, graças ao perdão, abrem as possibilidades da esperança ${ }^{41}$.

Entretanto, devemos lembrar que Levinas não é o primeiro a fazer do Outro a chave da subjetividade ética, pois, além de Husserl (rapidamente lembrado aqui), já se encontra em Kant uma definição muito explícita [da] pessoa subjetiva quando [nos "Fundamentos da metafísica dos costumes", afirma que] uma pessoa é aquele sujeito cujas ações são suscetiveis de imputação ${ }^{41}$.

Por fim, talvez valha a pena lembrar também o filósofo Bertrand Russell, que, num texto sobre a relação entre ética e política, considerava que seria do 
tipo de relação estabelecida com a alteridade que dependeria a própria sobrevivência da espécie humana e que deveríamos, portanto, esperar [que] $a$ humanidade, pelo menos à beira do precipício, pare e reflita, e se dê conta de que, talvez, até o bem-estar daqueles que odiamos não seria um preço alto demais para pagar em troca de nossa sobrevivência ${ }^{42}$.

Em síntese, o diálogo empático, que tentamos aqui delinear, parece ser a condição de possibilidade para a construção de uma espécie de meta-ponto de vista complexo, capaz de ultrapassar, pelo menos de modo argumentativo, as diferenças tidas como antitéticas. Mas, para tanto, deve-se ser capaz de distinguir sem separar e relacionar diferenças sem confundir seus traços específicos, pois acreditamos que este seja um possível caminho dialético para a gestão dinâmica da desordem mais que a produção estável e artificial da ordem ${ }^{43}$.

\section{Referências}

1. Smith A. Teoria dos sentimentos morais. São Paulo: Martins Fontes; 1999. p. 5.

2. Lalande A. Religion. In: Lalande A. Vocabulaire technique et critique de la philosophie. Paris: Presses Universitaires de France; 1972. p. 915-8.

3. Kant I. Crítica da razão prática. São Paulo: Martins Fontes; 2008. p. 25.

4. Kant I. Crítica da faculdade do juízo. Lisboa: Imprensa Nacional/Casa da Moeda; 1998. p. 46, 452.

5. Mautner T. Análise. In: Mautner T, diretor. Dicionário de filosofia. Lisboa: Edições 70; 2010. p. 57.

6. Mautner C. Agnosticismo. In: Mautner T, diretor. Op. cit. p. 44.

7. Auvray-Assayas C. Religio. In: Cassin B, organizadora. Vocabulaire européen des philosophies. Paris: Seuil/Le Robert; 2004. p. 1.069-71.

8. Derrida J. Pardonner: I' impardonnable et I' imprescriptible. Paris: L'Herne; 2005. p. 30-1.

9. Derrida J. Foi et savoir. Paris: Seuil; 2001. p. 29.

10. Mucchielli A. Approche empathique. In: Mucchielli A, diretor. Dictionnaire des méthodes qualitatives en sciences humaines. Paris: Armand Colin; 2011. p. 70.

11. Ducrot O, Todorov T. Dictionnaire encyclopédique des sciences du langage. Paris: Seuil; 1972. p. 388.

12. Blackburn S. Tolerância. In: Blackburn S. Dicionário Oxford de filosofia. Rio de Janeiro: Jorge Zahar; 1997. p. 390.

13. Habermas J. Theorie des kommunikativen Handels. Frankfurt am Main: Suhrkamp; 1981.

14. Habermas J. Erläuterungen zur Diskursethik. Frankfurt am Main: Suhrkamp; 1991.

15. Calogero G. No rule for thinking, only one rule for meaning. Logique \& Analyse. 1962; 5(20):181198, p. 181. [Internet]. [acesso 17 out 2014]. Leuven: Peeters; Disponível: http://virthost.vub. ac.be/Inaweb/ojs/index.php/LogiqueEtAnalyse/search/search

16. Levinas E. Le temps et l'autre. Paris: PUF; 2001. p. 75, 63.

17. Levinas E. Entre nós: ensaios sobre a alteridade. Petrópolis: Vozes; 1997. p. 17.

18. Levinas E. Op. cit; 1997. p. 26-31.

19. Capone Braga G, Ivaldo M. Dialettica. In: Melchiorre V, diretor. Enciclopedia filosofica. Milão: Bompiani; 2006. v. 3, p. 2.814.

20. Cassin B. Dialectique. In: Vocabulaire européen des philosophies, op. cit. p. 306-7.

21. Casper B. Dialogo. In: Enciclopedia filosófica, op. cit. p. 2.818.

22. Abbagnano N. Empatia. In: Abbagnano N. Dizionario di filosofia. Milão: TEA; 1998. p. 297.

23. Pinotti A. Empatia. Storia di un'idea da Platone al postumano. Roma: Laterza; 2011. p. IX.

24. Husserl E. Meditações cartesianas. Introdução à Fenomenologia. São Paulo: Madras; 2001. p. 106.

25. Boella L, Fornaro M. Einfühlung. In: Enciclopedia filosofica, op. cit. v. 4, p. 3.287.

26. Pinotti A. Op. cit. p. V.

27. Kemp P, Rendtorff JD. Vulnerabilidade (principio de). In: Hottois G, Missa J-N, organizadores. Nova enciclopédia da bioética. Lisboa: Inst. Piaget; 2003. p. 688.

28. Pinotti A. Op. cit. p. VIII.

29. Rifkin J. The empathic civilization: the race to global consciousness in a world in crisis. Nova York: Penguin; 2009. p. 1-3.

30. De Waal FBM. A era da empatia. São Paulo: Companhia das Letras; 2010. p. 9-16.

31. De Waal FBM. Op. cit. p. 309-10.

32. De Waal FBM. Op. cit. p. 315.

33. De Waal FBM. Op. cit. p. 313.

34. De Waal FBM. Op. cit. p. 101, 29, 98.

35. Pinotti A. Op. cit. p. XII.

36. Auvray-Assayas C. Op. cit. p. 1.069.

37. Moschetti AM, Grassi P. Religione. In: Enciclopedia filosofica. Op. cit. p. 9.579.

38. Huxley TH. Agnosticism. [Internet]. [acesso 17 out 2014]. Disponível: http://infidels.org/library/ historical/thomas_huxley/huxley_wace/part_02.html

39. Kant I. Crítica da razão prática. São Paulo: Martins Fontes; 2008. p. 220-2.

40. Wittgenstein L. Investigações filosóficas. São Paulo: Abril Cultural; 1975. 
41. Fontanille J. Sémiotique et éthique. [Internet]. [acesso 17 out 2014]. 2007. Disponível: http:// epublications.unilim.fr/revues/as/2445

42. Russell B. Dall'etica alla politica. In: Russell B. Un'etica per la politica. Roma: Laterza; 2008. p. 139.

43. Revelli M. Finale di partito. Torino: Einaudi; 2013. p. XI.

Recebido: 17. 9.2014

Revisado: $\quad 2.10 .2014$

Aprovado: 27.10 .2014 